\title{
PENGUJIAN DIMENSI CAUSE- RELATED MARKETING (CRM) TERHADAP LOYALITAS PRODUK AIR MINUM DALAM KEMASAN MEREK AQUA (STUDI PADA MAHASISWA UNIVERSITAS BORNEO TARAKAN)
}

\author{
TESTING OF CAUSE RELATED MARKETING (CRM) DIMENSIONS TO \\ DRINK WATER LOYALTY IN AQUA BRAND PACKGING (STUDY ON \\ UNIVERSITY STUDENTS BORNEO TARAKAN)
}

\begin{abstract}
Siti Aisyah $^{1)}$, Syahran ${ }^{2)}$
Abstrak: Penelitian ini membahas mengenai Pengujian dimensi Cause Related Marketing (CRM) terhadap loyalitas air minum dalam kemasan merek AQUA. Desain penelitian yang digunakan didasarkan oleh penelitian Douwe van de Brink, Gaby Odekerken-Schroder dan Pieter Pauwels (2006). Pengujian variabel independen Cause Related Marketing (CRM) yang diukur melalui empat buah dimensi yakni congruency, duration, amount of resources invested dan executive management involvement dan satu variabel dependen adalah loyalitas merek. Penelitian ini adalah penelitian kuantitatif di mana data primer dikumpulkan melalui angket atau kuesioner yang disebar kepada 263 responden yang mengkonsumsi air minum dalam kemasan merek AQUA dan juga mengetahui iklan "Satu Untuk Sepuluh" di Universitas Borneo Tarakan. Hasil penelitian menunjukkan bahwa Variabel Cause Related Marketing (CRM). Hasil analisis regresi dari variabel CRM menunjukkan tidak semua dimensi bepengaruh positif dan juga signifikan terhadap loyalitas merek. Dari keempat dimensi yaitu congruency, duration, amount of resources invested dan executive management involvement hanya duration, amount of resources invested yang berpengaruh positif dan signifikan terhadap loyalitas merek. Dari semua faktor yang membuat kampanye CRM sukses adalah lamanya waktu kampanye dan sumber daya yang di investasikan.
\end{abstract}

Kata Kunci : Cause Related Marketing, Congruency, Duration, Amount Of Resources Invested, Executive Management Involvement Dan Loyalitas Merek

Abstract: This study aims to examine the dimension of Cause Related Marketing (CRM) against packaging drink water loyalty brand AQUA. The research design used by research based Douwe van de Brink, Gaby Odekerken-Schroder Pauwels and Pieter (2006). Testing variables independent of Cause Related Marketing (CRM) as measured through four dimensions i.e. congruency, duration, amount of resources invested and executive management involvement and one dependent variable is brand loyalty. This research is quantitative research in which primary data collected via the question form or questionnaire presented to the 263 respondents who consume bottled drinking water AQUA brand and also know the advertising "one to Ten" at the University Borneo Tarakan. The results showed that Variable Cause Related Marketing (CRM). The results of the regression analysis of the variables of the CRM show not all the dimensions of influential positive and also significantly to brand loyalty. From the fourth dimension, 
namely congruency, duration, amount of resources invested and executive management involvement just duration, the amount of resources invested are positive and significant effect against the brand loyalty. Of all the factors that make CRM successful campaign is the length of time campaign and resources on investing.

Keywords: cause related marketing, congruence, duration, amount of resources invested, executive management involvement and brand loyalty

\section{LATAR BELAKANG}

Menghadapi kondisi persaingan produsen air minum dalam kemasan (AMDK) melakukan upaya untuk menjaring konsumen. Produsen air minum dalam kemasan (AMDK) di Indonesia melakukan penawaran produk melalui iklan yang menampilkan model yang bagus dan menekan bahwa produk air minum dalam kemasan yang diproduksinya berkualitas baik. Perusahaan telah menyadari bahwa, kelangsungan suatu usaha tak hanya ditentukan oleh adanya keuntungan yang memadai, tetapi juga keserasian eksistensi sosial perusahaan tersebut di masyarakat. Doing Great by Doing Good (Kotler and Lee, 2005: 10-11), perusahaan-perusahaan menerapkan keseimbangan integritas antara pertimbangan-pertimbangan

ekonomi, sosial dan lingkungan yang umum dikenal sebagai

Corporate Sosial Responsibility (CSR).

Menurut Kotler dan Lee (2005) menyatakan bahwa kegiatan corporate social responsibility (CSR) terdiri dari enam bentuk yaitu socialresponsibility business practices, cause-related marketing, community volunteering, corporate cause promotion, corporate philanthropy dan corporate social marketing. Perusahaan melaksanakan kegiatan sosial melalui aktifitas pengumpulan dana yang didapat dari sebagian keuntungan dari hasil penjualan produknya, penerapan inisiatif CSR yang berbasis pada strategi pemasaran perusahaan, yaitu konsep Cause-Related Marketing (CRM). Pringle dan Thompson (1999) menjelaskan bahwa CRM merupakan sebuah konsep pemasaran yang berfungsi sebagai strategic positioning dan alat pemasaran yang menghubungkan perusahaan atau sebuah brand dengan tujuan sosial (social cause) yang mempunyai sifat simbiosis mutualisme. Jenis program ini merupakan pemberian donasi kepada penerima (objek donasi) yang bersumber pada jumlah pendapatan dari hasil penjualan produk (Polonski dan Speed, 2001). Cause Related Marketing (CRM) merupakan kegiatan yang pada dasarnya merupakan penjabaran dari CSR yang diaplikasikan dalam aliansi sosial sekaligus menambah persepsi terhadap nilai yang selanjutnya akan mempengaruhi keputusan pembelian dan membentuk pada kesetiaan (loyality). Dalam program Danone AQUA yaitu "Satu Untuk Sepuluh" dengan slogan "ada terus, terus ada" beberapa tahun lalu dan berkomitmen dalam menjalankan programnya. Perusahaan AQUA 
berkerjasama dengan LSM internasional yakni Action Contre la Faim (ACF) yang menyedian air bersih, serta penataran tentang sanitasi dan hygiene (WASH) di daerah Timur, Tengah, Selatan, provinsi Nusa Tenggara Timur (NTT). Program "Satu Untuk Sepuluh" oleh AQUA menjadi program investasi yang inovatif bagi masyarakat.

\section{RUMUSAN MASALAH}

Berdasarkan latar belakang tersebut maka rumusan masalah yang akan diteliti adalah: Apakah Congruency,Duration, Amount of Resources Invested, Executive Management Involvement berpengaruh terhadap loyalitas air minum dalam kemasan (AMDK) merek Aqua?

\section{TUJUAN PENELITIAN}

Berdasarkan latar belakang dan rumusan masalah di atas, maka tujuan penelitian ini adalah: Untuk mengetahui pengaruh Congruency, Duration, Amount Of Resources Invested, Executive Management Involvement berpengaruh terhadap loyalitas (AMDK) merek Aqua.

\section{TINJAUAN PUSTAKA}

$\underline{\text { Loyalitas Merek (Brand Loyalty) }}$

Menurut Tjahyadi (2006) dalam Alexander (2014), istilah loyalitas menujukan pada kesetiaan pelanggan pada objek tertentu, seperti merek, produk, jasa, atau toko. Peter dan Olson (2000) menyebutkan bahwa loyalitas merek dapat diketahui dengan melihat pembelian ulang dan kepuasan terhadap suatu merek tertentu. Dikuatkan oleh Jacoby dan Keyner (1973), Aaker (1991), serta Susan Fournier dan Julie L. Yao (1997), untuk mengukur loyalitas merek, yaitu: Future Purchase, Bahwa ekuitas merek tidak hanya nilai langsung tapi juga nilai jangka panjang menjamin arus pendapatan masa depan, sehingga diharapkan pengetahuan mengenai merek (Awareness dan image) untuk mempengaruhi perilaku konsumen dimasa depan (Aaker, 1991; 1996).

Measuring Satisfaction.

Kepuasan merek dapat didefinisikan sebagai hasil evaluasi subjektif bahwa memilih merek alternatif memenuhi atau melampaui ekspektasi (Bloemer dan Kasper, 1995). Linking of The Brand. Bennet (1996), menyarankan bahwa untuk memulai sebuah hubungan satu pihak harus disukai oleh yang lain. Bagi konsumen hubungan dengan merek, konsumen harus lebih dulu menyukai sebuah merek. Commitment. Kesukaan pelanggan akan suatu merek akan mendorong mereka untuk membicarakan merek tersebut kepada orang lain baik dalam taraf menceritakan atau sampai tahap merekomendasikan.

\section{Cause-Related Marketing(CRM)}

Polonski dan Speed (2001) menjelaskan cause-related marketing (CRM) merupakan donasi dari perusahaan kepada penerima atau cause yang berbasis dari jumlah pendapatan yang diterima 
perusahaan dari hasil penjualan produk. Selanjutnya, Varadarajan dan Menon (1988) menyatakan cause-related marketing adalah aktivitas pemasaran, suatu cara agar perusahaan menjadi baik dengan melakukan kegiatan yang baik. Sebuah kampanye CRM memiliki dua tujuanuntuk mendukung cause sosial, dan untuk meningkatkan kinerja pemasaran (Varadarajan dan Menon, 1988). Pengaruh CRM sebagai komponen integral perusahaan, strategi pemasaran menuntut keputusan dari pihak perusahaan tentang berbagai dimensi.Farmer dan Hogue dalam Vadarajan dan Menon (1988) menjelaskan bahwa evaluasi dari kegiatan CRM tidak harus didasarkan pada pertimbangan pemasaran sebagai bentuk efektivitas dalam penjualan. Dengan kata lain, Cause-Related Marketing (CRM) dapat dipahami sebagai aktifitas perusahan untuk menghubungkan dukungan mereka terhadap suatu cause dengan tujuan bisnis sehingga tercipta manfaat yang saling menguntungkan bagi penciptaan nilai sosial dan shareholder (Kusumawati, 2009). Brink et al. (2006) menyatakan bahwa pola dalam kampanye CauseRelated Marketing (CRM) terdiri dari dua bentuk, yaitu pola strategis dan taktis. Pola CauseRelated Marketing(CRM) taktis memiliki perbedaan yang mendasar dengan pola Cause-Related Marketing(CRM) strategis, namun memiliki dimensi yang sama, yaitu kesesuian (congruence), durasi (duration), jumlah investasi (amount of invested), dan keterlibatan manajemen puncak (executive management involvement).

\section{Congruency}

Dalam Xiaoli dan Kwangjun
(2007), Congruence dalam

CauseRelated Marketing (CRM) bahwa seluruh tindakan dirasakan antara keterkaitan merek dan cause dengan beberapa basis kognitif. Menurut Xiaoli Nan dan Kwangjun Heo (2007), strategi pemasaran pada umumnya mengasosiasikan produk dengan objek yang memiliki atributatribut positif. Varadarajan dan Menon (1988) serta Ellen et al. (2000) dalam Laudreth (2002:21), mendefinisikan congruency dalam konteks Cause-Related Marketing (CRM) dicapai jika terdapat pandangan kesesuaian antara cause dengan lini produk, citra merek, positioning merek atau target pasar dari perusahaan.Dalam hal ini Prajecus dan Olsen (2004) mengemukakan bahwakesesuaian antara bisnis inti dari perusahaan dan isu sosial yang bergabung dalam kegiatan kampanye CRM yang diselenggarakan.

\section{Duration}

Miller (2002) menyarankan bahwa perusahaan perlu untuk menunjukkan komitmen perilakunya dalam CauseRelated Marketing(CRM).Hal ini dikarenakan komitmen perusahaan dapat mengarahkan pada pembentukan loyalitas merek dari pada para konsumennya. Salah satu faktor yang dapat menunjukkan komitmen perusahaan adalah durasi 
dari pelaksanaan program CauseRelated Marketing(CRM). Lebih lanjut, Vadarajan dan Menon (1998) menjelaskan bahwa durasi dari pelaksanaan Cause-Related Marketing (CRM) terdiri dari jangka pendek, menengah dan panjang. Komitmen waktu jangka panjang dari CRM adalah terhitung dalam tahunan, sedangkan komitmen waktu janka pendek sekitar 6 (enam) bulan atau kurang (Drumwright, 1996).Drumwright

menyebutkan bahwa komitmen waktu jangka panjang, yang dihitung dalam perkalian waktu menunjukkan bahwa kampanye CRM meningkatkan penjualan.

\section{Amount of Resources Invested}

Investasi sumber daya dalam program Cause-Related Marketing (CRM) ditujukan dalam bentuk pembelian donasi berupa sejumlah porsi tertentu. Namun, bentuk sumber daya dalam program CauseRelated Marketing (CRM) juga dapat ditingkatkan dengan menginvestasikan waktu atau keahlian pegawai, tenaga sukarelawan dan berbagai alternatif non moneter lainnya (Miller, 2002). Sebuah kerangka kerja holistik, penting untuk menganalisis bagaimana kerangka kerja praktis dari suatu manajemen yang terkait. Pertama, kerangka kerja tidak dipahami sebagi alat operasional seperti kerangka kerja manajemen proyek, melainkan sebagai standarisasi yang menyediakan semua komponen untuk merancang dan menetapkan praktik CRM yang berhasil (Christofi et al. 2015). $\underline{\text { Executive Management Involvement }}$

Menurut Macleod (2001) keterlibatan yang nampak antusias dari para eksekutif to management dapat meningkatkan kredibilitas dari program CRM (Brink et al. 2006). Lebih lanjut, Smith (1994) berpendapat bahwa penurunan dari kontribusi filantropi pada pertengahan tahun 1990 diantaranya karena adanya penurunan dalam keterlibatan CEO. Di sebuah organisasi CEO yang bertanggung jawab secara sosial, orang yang menginvestasikan waktu, energi, dan kreativitas mereka dalam meluncurkan sebuah kebijakan atau inisiatif yang bertanggung jawab sosial dalam bisnis merekakarena mereka percaya itu adalah hal yang benar untuk dilakukan (Drumwright1994).

\section{$\underline{\text { Konseptual Model dan Hipotesis }}$}

Hipotesis didefinisikan sebagai hubungan yang diperkirakan secara logis diantara dua atau lebih varibel yang diungkapkan dalam bentuk pernyataan yang dapat di uji. Hipotesis didefinisikan sebagai hubungan yang diperkirakan secara logis diantara dua atau lebih varibel yang diungkapkan dalam bentuk pernyataan yang dapat di uji. Dengan menguji hipotesisdan menegaskan perkiraan hubungan, diharapkan bahwa solusi dapat ditemukan untuk mengatasi masalah yang dihadapi (Uma Sekaran, 2006:135). Sesuai dengan pertanyaan penelitian yang telah disebutkan sebelumnya, maka hipotesis utama dalam penelitian ini adalah: 
1. Hubungan antara Dimensi CauseRelated Marketing (CRM) Congruence terhadap loyalitas merek Penelitian yang dilakukan oleh Prejeus dan Olsen (2004) mengemukakan bahwa kesesuaian antaramerek dan amal dapat memiliki dampak yang luar biasa pada keberhasilan kampanye CRM. Di perkuat oleh penelitian sebelumnya oleh Strahilevitz dan Meyers (1998), telah mengusulkan bahwa kesesuaian antara merek dan cause dapat mempengaruhi keberhasilan CRM. Sebuah perusahaan lebih efisien untuk membuat donasi produk yang sesuai dengan initi bisnis (Ellen, Mohr dan Webb, 2000). Dan kampanye CRM dipandang sukses ketika cause konpatibel atau cocok dengan perusahaan (Dwumwright, 1996).

2. H1 : Congruency berpengaruh positif terhadap loyalitas merek.

Hubungan antara Dimensi CauseRelated Marketing (CRM) Duration terhadap loyalitas merek Penelitian yang dilakukan oleh Cheron (2012) mengemukakan bahwa kampanye CRM yang berlangsung selama jangka waktu panjang cenderung dipandang positif oleh konsumen. Till dan Nowak (2000) menyebutan bahwa kampanye Cause-Related Marketing (CRM) akan lebih efektif ketika informasi mengenai kampanye tersebut secara terus menerus diterapakan dalam jangka waktu yang panjang dibandingkan jika informasi hanya diberikan sesekali atau tidak berkesinambungan.

H2 : Duration berpengaruh positif terhadap loyalitas merek.

3. Hubungan antara Dimensi CauseRelated Marketing (CRM) Amount of Resources Invested terhadap loyalitas merek. Varadarajan dan Menon (1988), indikator program kampanye CauseRelated Marketing (CRM) sebagai alat strategis termasuk investasi sumber daya terhadap perkembangan dan implementasi program sangat dibutuhkan. Hasil Inovasi organisasi memberikan kontribusi, secara tidak langsung untuk keberhasilan kampanye CRM. Sebuah perusahaan sukses pada kampanye CRM yang lebih tinggi ketika karyawan memiliki pengalaman yang berbeda (Christofi et al, 2015). H3 : Amount of resources involvement berpengaruh positif terhadap loyalitas merek.

4. Hubungan antara Dimensi CauseRelated Marketing (CRM) Executive Management Involvement terhadap loyalitas merek.

Keterlibatan manajemen puncak memiliki dampak yang besar untuk memberikan kontribusinya dalam kegiatan promosi, keterlibatan tersebut menjadi paling efektif dalam meningkatkan keunggulan kompetitif (Porter dan kremer, 2002). Penelitian Drumwright (1996), menunjukkan bahwa keterlibatan manajemen puncak lebih tinggi dari biasanyadi enam dari sembilan kampanye campuran dan non ekonomi. 
Selanjutnya keterlibatan manajemen puncak yaitu Pejabat eksekutif(CEO) atau chief operating officer (COOs) mereka lebih dalam dan aktif terlibat dalam kampanye sosialdaripada kampanye standar, dan persepsi mereka berkumpul dengan laporan bawahan mereka Drumwright (1996). H4 : Excutive Management Involvement berpengaruh positif terhadap loyalitas merek.

Berdasarkan landasan teori dan penelitian sebelumnya pengaruh antara variabel maka untuk merumuskan hipotesis, kerangka penelitian ini dapat dijelaskan pada gambar berikut:

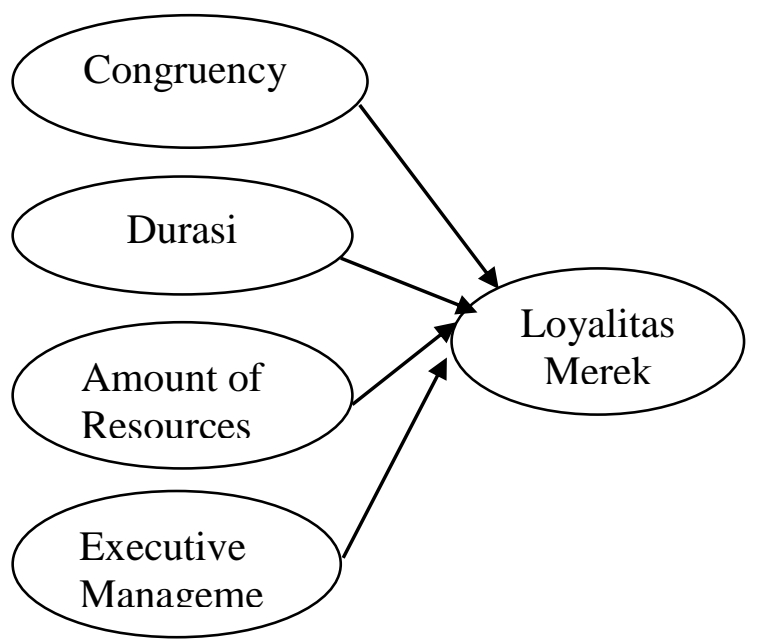

Gambar 1. Kerangka Teoritis Pengaruh Couse-Related Marketing (CRM) Terhadap Loyalitas AMDK Merek AQUA: Studi pada Mahasiswa Univesitas Borneo Tarakan

\section{METODOLOGI PENELITIAN}

Desain Penelitian

Jenis penelitian ini adalah kuantitatif dengan menggunakan metode penelitian survei pendekatan explanatory research atau studi kausal yang dimaksudkan agar mampu menyatakan bahwa variabel $\mathrm{X}$ menyebabkan variabel Y (Sekaran, 2007: 164). Metode survey adalah penelitian yang melibatkan instrument penelitian yang disusun berdasarkan indikator-indikator yang jelas dan untuk mengetahui suatu fenomena tertentu (Singaribun dan Masri, 2001:3). Desain penelitian yang digunakan yakni penelitian cross sectional, yaitu tipe desain penelitian yang berupa pengumpulan data dari sampel tertentu yang hanya dilakukan satu kali atau tepatnya single cross sectional, dimana kegiatan pengumpulan data dilakukan dari satu responden untuk satu waktu saja (Malhotra, 2005:94).

\section{Objek dan Lokasi Penelitian}

Menurut Sugiyono (2009:38) pengertian objek penelitian adalah suatu atribut atau sifat atau nilai dari orang, objek atau kegiatan yang mempunyai variasi tertentu yang ditetapkan oleh penelitian dipelajari dan kemudian ditarik kesimpulannya. Objek pada penelitian ini adalah AQUA. Aqua Grup menggunakan pendekatan bisnis yang mengkombinasikan tujuan ekonomi, sosial dan lingkungan untuk pencapaian kinerja dan nilai inti perusahaan. Lokasi penelitian adalah tempat dimana sebenarnya penelitian dilakukan dan dimana sebernarnya 
peneliti menangkap keadaan dari objek-objek yang sedang diteliti. Lokasi penelitian adalah di Universitas Borneo Tarakan provinsi Kalimantan Utara, Indonesia. Universitas Borneo Tarakan didirikan oleh Yayasan Pinekindi pada tahun 1999 dan berubah statusnya menjadi negeri oleh Peraturan Presiden RI No. 19 yang dituangkan kedalam Peraturan Presiden RI No. 65 Tahun 2010 Tentang Pendirian Universitas Borneo Tarakan di Jakarta, pada tanggal 19 November 2010 (www.wikipedia.org).

\section{$\underline{\text { Populasi dan Sampel }}$}

Target kelompok populasi dalam penelitian ini adalah Mahasiswa Universitas Borneo Tarakan, Kalimantan Utara yang mengkonsumsi produk Air Minum Dalam Kemasan (AMDK) merek AQUA. Metode pengambilan sampel yang digunakan peneliti adalah teknik Non Probability Sampling yaitu teknik pengambilan sampel yang tidak memberikan peluang atau kesempatan yang sama bagi setiap unsur atau anggota populasi untuk menjadi sampel (Sugiyono, 2008:122).Menurut Aaker et al (1998), nonprobability sampling diharapkan mampu menghilangkan persoalan biaya dan pengembangan suatu kerangka sampling. Pemilihan unit sampel didasarkan pada pertimbangan atau penilaian subjektif dan tidak pada penggunaan teori probabilitas (Velany, 2008). Metode nonprobability sampling yang digunakan adalah convenience sampling dimana pengambilan sampel dilakukan dari responden yang termudah diakses mengetahui Program "Satu Untuk Sepuluh - Ada Terus, Terus Ada" yang diselenggarakan oleh Aqua, dan bersedia menjadi responden (Malhotra, 2005:372). Pada tahap ini ditentukan kerangka sampling yakni stratifikasi konsumen seperti jenis kelamin, usia dan fakultas. Roscoe (1975) dalam Sekaran (2006:60) mengusulkan aturan untuk menetukan ukuran sampel lebih dari 30 atau kurang dari 500 adalah tepat untuk kebanyakan penelitian. Penelitian dengan faktor analisis harus memiliki observasi sejumlah 10 kali jumlah indikator yang dianalisis (Hair, 2003:333), maka penelitian ini terdapat 34 pertannyaan sehingga ukuran sampel minimal adalah 340 responden Responden dalam penelitian ini adalah konsumen produk air mineral dalam kemasan merek AQUA yang berjumlah 340 responden. Dalam penelitian ini teknik pengambilan sampel yang digunakan adalah non probability sampling. Metode pengambilan sampel yang digunakan adalah convenient sampling.

\section{HASIL DAN PEMBAHASAN}

\section{Deskripsi Responden}

Responden dalam penelitian ini adalah konsumen produk air mineral dalam kemasan merek AQUA yang berjumlah 263 responden. Dalam penelitian ini teknik pengambilan sampel yang digunakan adalah non probability sampling. Metode pengambilan 
sampel yang digunakan adalah convenient sampling. Pengambilan sampel dilakukan dari responden yang termudah diakses mengetahui program "Satu Untuk Sepuluh - Ada Terus, Terus Ada" yang diselenggarakan oleh Aqua, dan bersedia menjadi responden (Malhotra, 2005:372). Dari 340 kuesioner yang tersebar, hanya 263 kuesioner yang kembali. Data tersebut diperoleh dari 263 responden, sehingga data yang akan diolah adalah sebanyak 263 data. Data yang akan diolah merupakan indikator pertanyaan dari variabel penelitian.

Hasil Pengujian

\section{Hasil Pengujian Uji Validitas}

Butir-butir pertanyaan yang mempunyai faktor loading yang valid yaitu $\geq 0,50$ menunjukan bahwa indikator-indikator yang ada merupakan satu kesatuan alat ukur yang mengukur suatu konstruk yang sama dan dapat memprediksi apa yang seharusnya dapat diprediksi. Item-item yang mengukur konsep yang sama akan memiliki korelasi yang tinggi dan berkorelasi rendah dengan item-item yang mengukur konsep yang berbeda (Sekaran, 2006). Hasil faktor analisis terlihat hanya pada variabel turunan yaitu congruency, Duration, Amount of Resources Invested, dan Executive Management Invested terdapat indikator yang harus dikeluarkan yaitu Co5, Co6, Du1, Du2, Am1, Am2, Am3, Am4, Ex4, Ex5

\section{$\underline{\text { Hasil Pengujian UJi Reliabilitas }}$}

Menurut Ghozali (2006), reliabilitas adalah alat ukur untuk mengukur suatu kuesioner yang merupakan indikator dari variabel atau konstruk. Suatu kuesioner dikatakan reliabel atau handal jika jawaban seseorang terhadap pernyataan adalah konsisten atau stabil dari waktu ke waktu. Pengukuran reliabilitas dapat dilakukan dengan uji statistik Cronbach Alpha ( $\alpha$ ). Suatu konstruk atau variabel dinyatakan reliabel jika memberikan nilai Cronbach Alpha> 0,70. Hasil pengujian reliabilitas yang disajikan pada lampiran 2 (dua) menunjukkan nilai rule of thumb Cornbach's Alpha berkisar antara 0,712 sampai 0,914 terdapat satu nilai rule of thumb Cornbach's Alpha yang menunjukkan $0,420,0,556$ dan 0,591 . Dengan demikian item yang memenuhi persyaratan reliabilitas.

\section{$\underline{\text { Hasil Uji Hipotesis }}$}

Uji hipotesis dalam analisis ini menggunakan SPSS dengan melihat nilai $\beta$, serta membandingkan dengan nilai thitung dengan ttabel. Pengujian hipotesis ini dengan menganalisis batasan statistic yang disyaratkan yaitu thitung diatas 1,98. Apabila hasil olah data menunjukkan nilai memenuhi syarat maka hipotesis penelitian yang diajukan dapat diterima

1. Hipotesis1:Congruency

berpengaruh positif terhadap loyalitas merek.

Ringkasan uji hipotesis menunjukkan bahwa hubungan 
tersebut memiliki $\quad \begin{array}{lll}0,084 & \text { dan }\end{array}$ thitung sebesar 1,016 signifikan pada $\mathrm{a}=0,05$ (one tailed) nilai ttabel 1,98. Nilai thitung> ttabel atau 1,016 < 1,98. Hal ini menunjukkan bahwa Congruency tidak berpengaruh positif tetapi signifikan terhadap loyalitas. Dengan demikian dapat disimpulkan bahwa hipotesis 1 ditolak.

2. Hipotesis2:Duration berpengaruh positif terhadap loyalitas merek.

Ringkasan hasil ujihipotesis menunjukkan bahwa hubungan tersebut memiliki nilai $\beta \quad 0,328$ dan thitung sebesar 4,174 signifikan pada $\mathrm{a}=0,05$ (one tailed) nilai ttabel 1,98. Nilai thitung > ttabel atau 4,174 $>1,98$. Hal ini menunjukkan bahwa duration berpengaruh positif dan signifikan terhadap loyalitas merek. Dengan demikian dapat disimpulkan bahwa hipotesis 2 diterima.

3. Amount of resources invested berpengaruh positif terhadap loyalitas merek

Ringkasan hasil uji hipotesis menunjukkan bahwa hubungan tersebut memiliki nilai $\beta \quad 0,340$ dan thitung sebesar 5,604 signifikan pada $\mathrm{a}=0,05$ (one tailed) nilai $\mathrm{t}$-tabel 1,98. Nilai thitung > ttabel atau 5,604 $>1,98$. Hal tersebut menunjukkan Amount of resources involved berpengaruh positif dan signifikan terhadap loyalitas merek. Dengan demikian dapat disimpulkan bahwa hipotesis 3 diterima.

4. Hipotesis 4 : Excutive Management Involvement berpengaruh positif terhadap loyalitas merek.

Ringkasan hasil ujihipotesis menunjukkan bahwa hubungan tersebut memiliki nilai $\beta 0,025$ dan thitung sebesar 0,336 signifikan pada $\mathrm{a}=0,05$ (one tailed) nilai ttabel 1,98. Nilai thitung > ttabel atau 0,336 $>$ 1,98. Hal tersebut menunjukkan Excutive Management Involvement tidak berpengaruh positif namun tidak signifikan terhadap loyalitas merek. Dengan demikian dapat disimpulkan bahwa hipotesis 4 ditolak.

\section{KESIMPULAN}

Setelah melalui proses pengumpulan data dan analisis terhadap hasil penelitian dengan menggunakan alat uji statistic linier regression pada SPSS 16.0 yang telah di bahasa pada bab 4, maka berikut ini beberapa kesimpulan yang dapat ditarik:

a. Dari hasil analisis, dapat diketahui bahwa pengaruh Cause Related Maketing (CRM) terhadap loyalitas merek adalah tidak terlalu signifikan. Hal ini didasarkan pada hasil perhitungan regresi linier yang menunjukkan bahwa Cause Related Marketing (CRM) hanya mampu menjelaskan loyalitas merek sebesar $32,1 \%$.

b. Dari hasil analisis, terdapat 2 (dua) dimensi Cause Related Marketing (CRM) yang berpengaruh secara positif dan signifikan terhadap variabel loyalitas merek yaitu dimensi 
Duration dan Amount of Resources Invested.

\section{SARAN}

Berdasarkan simpulansimpulan yang diperoleh dalam penelitian ini, maka terdapat beberapa saran yang ingin peneliti ajukan terkait dengan tema dan tujuan penelitian ini, antara lain sebagai berikut:

a. Kampanye Cause Related Marketing (CRM) yang dilaksanaakn oleh AQUA memberikan pengaruh terhadap loyalitas merek dari konsumen. Akan tetapi, perusahaan diharapkan mampu mempertahankan loyalitas merek perusahaan yang baik dimata konsumen.

b. Kesuksesan suatu kampanye yang memiliki dimensi sosial salah satunya ditentukan oleh persepsi positif dari target audiens yang tercipta karena adanya integrasi informasi yang baik dalam benak mereka. Oleh karena itu, pihak manajeen AQUA perlu untuk memberikan informasi yang lebih banyak mengenai kegiatan sosial yang dilakukan termasuk kampanye Cause Related Marketing (CRM) kepada para konsumen.

c. Kampanye Cause Related

Marketing (CRM) yang dilaksanakan oleh AQUA memiliki keunggulan yang diperoleh melalui dimensi Duration dan Amount of Resouces Invested. Hal ini dikarena dimensi tersebut memiliki pengaruh positif dan signifikan terhadap loyalitas merek. Oleh karena itu, pihak manajemen AQUA sebaiknya tetap fokus berinovasi untuk mempertahankan nilai tersebut jika tetap memutuskan melanjutkankan kampanye Cause Related Marketing (CRM) yang telah dilaksanakan. d. Bagi penelitian selanjutnya disarankan untuk mengembangkan dengan menambahkan beberapa sampel penelitian, bukan hanya di Universitas Borneo Tarakan tetapi juga daerah lainnya, sehingga dapat diperoleh hasil penelitian dengan tingkat generalisasi yang lebih tinggi.

\section{DAFTAR PUSTAKA}

$\begin{array}{lr} & \text {,Badan Pusat Statistik. } \\ 2015 . & \text { Banyaknya } \\ \text { Desa/Kelurahan } \text { Menurut } & \text { Jenis } \\ \text { Lingkungan Hidup.(Online). } \\ \text { (www.bps.com). }\end{array}$

Aaker, David A. 1991. Managing BrandEquity: Capitalizing on the value of a brand name. New York: Free Press.

Aaker, David A. 1996. Measuring Brand Equity Across Products and Markets: California Management Review.(Vol. 38 No. 3).

Abbo, Marie-Helene. Brand Association, costumers; attitudes and cause related maketing: An Explanatory Study. 5-17.

Barone, Michael J. Miyazaki, Anthony D dan Taylor, 
Kimberly A. 2000. The Influence of Couse-Related Marketing on Consumer Choice: Does One Good Turn Deserve Another?.Journal of the Academy of Marketing Scince. (Volume 28, No. 2, hal: 248-262).

Bennet, R. 1996. Relationship Formation and Governance in Consumer Markets: Transactional Analysis versus the Behaviorist Approach. Journal of Marketing Management. (Vol. 12, 417-436).

Bidang Akademik Kemahasiswaan dan Kerjasama. Jumlah data mahasiswa Universitas Borneo Tarakan. 2016. (Online).

(www.bakk.bornoe.ac.id).

Bloemer, J. M. M, dan Kasper, H. D. P. 1995. The Complex Relationship Between Consumer Satisfaction and Brand Loyalty. Journal of Economic Psychology. (Vol. 16, 311-329).

Camison C dan Lopez A, Villar. 2012. Organizational Innovation as an Enabler of Technological Innovation Capabilities and Firm Performance. Journal of Business Research.(Vol. 67, 2014, hal: 28912902).

Camison, Cesar dan Villar-Lopez, Ana. 2012. Organizational Innovation as an Enable of Technological Innovation Capabilities and Firm Performance. Journal of
Business Research.(Vol. 67, 2891-2902).

Chernatony, de Leslie. 1998. Brand Building.The Marketing Book Fifth Edition. (Michael J. Baker). Burlington MA: ButterworthHeinemann.

Cheron, Emmanuel, Florian Kohlbacher, Kauru Kusuma. 2012. The Effects of BrandCause Fit and Campaign Duration on Consumer perception of Cause-Related marketing in Japan. Journal of Consumer Marketing. (Vol. 29, 357368).

Chi, H.K, Yeh, H.R, dan Yang Y.T. (2009). The Impact of Brand awareness on Consumer Purchase Intention: The Mediating Effect of Perceived Quality and Brand Loyalty. The Journal of International Management Studies. 4 (1) 135-144.

Christofi, Michael, Leonidou, Erasmia, Vrontis, Demetris, Kitchen dan Papasolomou, Ioanna. 2015. Inovation and Cause-Related marketing Success: a Conceptual Framework and Propositions. Journal of Service Marketing. (Vol. 29, 354-366).

Daw, Jocelyne. 2006. Cause Marketing for nonprofits: partner for purposepassion, and profit. New Jersey: John Wiley \& Sons.

Deans, PC dan D, A Ricks. 1991. MIS research: A Model for 
Incorporation the International Dimension. The Journal of High Technology Management Research.

Drumwright, Minette E. 1996. Company Advertising With a Social Dimension: The Role of Noneconomic Criteria. Journal of Marketing. (Vol. 60, 71-87).

Elkington, J. 1997. Jacoby, Jacob dan Kyner, David B. 1973. Brand Loyalty Vs. Repeat Purchasing Behavior. Journal of Marketing Research. (Vol. X, 1-9). Cannibals With Forks: The Triple Bottom Line of 21st Century Bussiness. Capstone:Oxford.

Ellen, Parn Scholder, Lois Mohr, dan Deborah Webb. 2000. Charitable programs and the Retailer: Do The Mix?.Journal of Retailing.

Firmansyah, Aditya. 2010. Analysis of Cause Related Marketing Application on Dove Sisterhood Program Toward Brand Loyalty of Dove Hairtherapy in Semarang. Thesis.

Diponegoro University.

Founrnier, Susan dan Yao, Julie L. 1997. Reviving Brand Loyalty: A Reconceptualization Framework of Consumer Brand

Relationships.Journal

Research in Marketing. (14, 451-472).

Guest, L. P. 1995. Brand LoyaltyTwelve Years later:
Journal of Applied Psychology. (Vol 12, No.1, hal: 25-31.

Hair, Joseph F. 2003.Marketing Research: Within a Changing Enviromental. Boston: McGrawHill/Irwin.

Industri Update. 2015. Air Minum Dalam Kemasan(AMDK). (Vol. 11, hal: 1-2).

Jacoby, J. 1971. A Model of MultiBrand Loyalty: Journal of Advertising Research. (Vol. 11, No. 1, hal: 53-77).

Jacoby, Jacob dan Kyner, David B. 1973. Brand Loyalty Vs. Repeat Purchasing Behavior. Journal of Marketing Research. (Vol. X, 1-9).

Kartajaya, Hermawan. 2005. Positioning, Diferensiasi, Brand. Jakarta: Gramedia Pustaka Utama.

Keller, Kevin, Lane. 1993. Conceptualizing,

Measuring, and managing Customer-Based Brand Equity. Juornal of Marketing. (Vol. 57, hal. 122).

Kotler, and Lee. 2005. Corporate Social Responsibility: Doing the Most Good for Your Company and Your Cause. John Wiley and Sons, Inc.

Kotler, Philip dan Keller, Kevin, Lane. 2008. Manajemen Pemasaran Edisi 13. (Bob Sabran). Jakarta:Penerbit Erlangga.

Kotler, Philip. 2000. Manajemen Pemasaran. Edisi Milenium 
1 dan 2. Jakarta: PT.

Prenhallindo

Kusumawati, Dyah, Puji. 2009. Pengaruh Cause Related Marketing (CRM) terhadap Loyalitas Merek The Body Shop. Skripsi.Jakarta : Universitas Indonesia.

Laforet, S. 2013. Organizational Innovation Outcomes in SMEs: Effects of age, size and sector. Journal of World Business. (Vol. 48, No.4, 490-502). 